\title{
BREVES COMENTARIOS A LOS MECANISMOS \\ IMPLEMENTADOS PARA LA PARTICIPACIÓN CIUDADANA \\ EFECTIVA DENTRO DE LA CERTIFICACIÓN AMBIENTAL POR \\ PARTE DE SENACE \\ BRIEF COMMENTS ON THE MECHANISMS IMPLEMENTED BY \\ SENACE FOR THE EFFECTIVE CITIZEN PARTICIPATION WITHIN THE \\ ENVIRONMENTAL CERTIFICATION PROCESS
}

\author{
Ana Paula Queirolo Romero* \\ Rubio Leguía Normand
}

Several mining extraction projects have been carried out disregarding the right of citizen participation of whom are affected by them. Factors such as gender or cultural gaps prevent its effective exercise. Therefore, to guarantee the right of citizen environmental participation, SENACE has incorporated Gender and Intercultural approaches to their environment assessment procedure.

In this article, the author stars to review the concept of citizen participation and then analyze its environmental variant. Later, analyzes the recognition and implications of citizen environmental participation within the context of environmental assessments, to further evaluate the need of incorporating the Gender and Intercultural approaches. Finally, analyzes the role of the State as a guarantor of the right of citizen participation and values the incorporation of these approaches made by SENACE.

KEY WORDS: Citizen environmental participation; SENACE; intercultural approach; gender approach; environmental impact assessment.
Muchos proyectos de extracción minera se han llevado a cabo pasando por alto el derecho a la participación ciudadana de quienes se ven afectados por ellos. Factores como las brechas de género y culturales impiden su ejercicio efectivo. Con el fin de garantizar el derecho a la participación ciudadana ambiental, el SENACE ha incorporado al procedimiento de evaluación ambiental dos enfoques: de Género e Intercultural.

En este artículo, la autora parte de revisar el concepto de participación ciudadana para luego analizarlo en su variante ambiental. Posteriormente, en el contexto de las evaluaciones ambientales, analiza el reconocimiento e implicancias de la participación ciudadana ambiental, para así evaluar la necesidad de considerar los Enfoques Intercultural y de Género. Finalmente, analiza el rol del Estado como garante del derecho a la participación ciudadana y valora la incorporación de estos enfoques por el SENACE.

Palabras ClaVe: Participación ciudadana ambiental; SENACE; enfoque intercultural; enfoque de género; evaluación de impacto ambiental.

\footnotetext{
Abogada por la Pontificia Universidad Católica del Perú con especialidad en Derecho Ambiental, Derecho Regulatorio y Buen Gobierno. Abogada asociada del Área de Recursos Naturales del Estudio Rubio Leguía Normand. Contacto: aqueirolo@rubio.pe.
}

Nota del editor: El presente artículo fue recibido por el Consejo Editorial el 28 de diciembre de 2018 y aceptado por el mismo el 29 de enero de 2019. 


\section{INTRODUCCIÓN}

En los últimos años, se han ido incrementando los conflictos socio ambientales en nuestro país, los cuales representan un número significativo $(66 \%$ del total de conflictos a nivel nacional) según la Defensoría del Pueblo ${ }^{1}$. Dichos conflictos se originan debido a la falta de confianza por parte de la población durante los procesos de evaluación ambiental de los proyectos extractivos. Y es que existe una pérdida de credibilidad hacia las instituciones del Estado -encargado de la evaluación del impacto ambiental- y la toma de decisiones frente a los intereses del privado.

Ante ello, el Servicio Nacional de Certificación Ambiental (en adelante, "SENACE")2, entidad adscrita al Ministerio del Ambiente encargada de la certificación ambiental, en su intento para consolidarse como un referente de buenas prácticas sociales y ambientales, además de la obligación que le subyace, ha introducido mecanismos garantistas durante la elaboración y evaluación de los Estudios de Impacto Ambiental detallados (en adelante, "EIA-d") para hacer efectiva la participación ciudadana y así, prevenir posibles conflictos en la población. Dichos mecanismos garantistas son el Enfoque Intercultural y el Enfoque de Género.

Así pues, se ha visto necesaria la incorporación del Enfoque Intercultural en la gestión pública y, sobretodo, en el proceso de participación ciudadana, a través de la realización de un intercambio abierto y respetuoso de opiniones entre grupos con diferentes tradiciones y orígenes étnicos, culturales, religiosos y lingüísticos. De igual manera, se ha priorizado la identificación de roles por género, de manera que se priorice el diálogo y la accesibilidad de la información para asegurar un enriquecimiento mutuo en la toma de decisiones públicas, en especial de grupos desfavorecidos históricamente.

En ese sentido, nuestro principal objetivo es analizar los procedimientos de participación ciudadana efectiva en el ciclo de la elaboración y evaluación del Estudio de Impacto Ambiental (en adelante, "EIA"), al ser un derecho fundamental que debe ser exigido.

Con dicha finalidad, se desarrollará una breve descripción del marco legal y aspectos institucionales del Sistema Nacional de Evaluación de Impacto Ambiental (en adelante, "SEIA"), de cara a la implementación de los mecanismos de participación ciudadana durante los procesos de evaluación de impacto ambiental.

\section{PARTICIPACIÓN CIUDADANA}

Como señala Pérez, las manifestaciones de la participación ciudadana son muy altas, más aún cuando se trata de consolidar un régimen democrático. Este fenómeno ocurre simultáneamente en diversos espacios, con culturas muy diversas, pero todas con el objetivo central de dar solución a problemas de interés social.

En las sociedades modernas la participación no se limita sólo a procesos electorales -participación política-, sino representa también una forma de participar, controlar y moderar el poder otorgado a los representantes políticos a través de formatos y mecanismos de participación ciudadana, que fortalezcan y nutran la vida democrática de la sociedad (1999, p. 178).

Al respecto, el Instituto Interamericano de Derechos Humanos señala lo siguiente:

La participación ciudadana va más allá del ejercicio de los derechos civiles y políticos. Es más abarcadora que la participación política, porque significa involucrarse de manera activa y consciente en la eliminación de los obstáculos a la igualdad, en la tarea de garantizar la plena vigencia y protección de los derechos humanos y la vida en democracia, así como en la construcción de una igualdad real para todas las personas que integran la sociedad (2002, p. 13).

De igual manera, la participación efectiva es catalogada por SENACE como un proceso, un derecho y una oportunidad para promover que la población manifieste sus opiniones, dudas y preguntas respecto de un proyecto de inversión, en forma responsable, y que estas sean absueltas por el titular del proyecto y tomadas en cuenta por la autoridad competente, en el marco del proceso de evaluación de impacto ambiental (2016, p. 5).

En ese sentido, es un proceso que proporciona información sobre el proyecto en un lenguaje claro y fomenta la escucha activa de los actores participantes; así, se reciben y toman en cuenta los aportes y comentarios de la población, fortaleciendo su participación, reduciendo la desigualdad y asegurando su representatividad. Finalmente, esta participación implica la adecuación de los meca-

\footnotetext{
1 Véase el Reporte de Conflictos Sociales Nro. 137 de la Adjuntía para la Prevención de Conflictos Sociales y la Gobernabilidad de la Defensoría del Pueblo.

2 En el año 2012, se creó el Servicio Nacional de Certificación Ambiental - SENACE mediante la Ley 29968.
} 
nismos empleados a las características culturales del grupo al que se dirige.

De esta forma, vemos cómo la participación ciudadana se encuentra inmersa en la sociedad en diversos ámbitos, los mismos que pueden ser categorizados de la siguiente forma:

- Participación Orgánica: Es "Autoadministración" o "Administración corporativa". Los integrantes no son solo colaboradores externos, sino que conforman la organización misma. Algunos ejemplos son los colegios profesionales y las juntas de usuarios de riego de la Autoridad Nacional del Agua - ANA.

- Participación Funcional: El ciudadano actúa funciones administrativas como colaborador desde fuera de la organización administrativa, sin perder su condición privada y sin incorporarse a un órgano administrativo. Algunos ejemplos son los trámites de consultas y de acceso a la información pública, los proyectos normativos antes de su publicación y la audiencia pública en el procedimiento de evaluación del impacto ambiental.

- Participación Cooperativa: El particular no se incorpora a la estructura de la Administración, no ejerce funciones públicas, solo realiza actividades de estricto carácter privado y colaboraciones voluntarias con las actividades de la Administración, promoviendo la tutela de los intereses públicos. Algunos ejemplos son aquellos en los que se involucran las Organizaciones no gubernamentales (en adelante, "ONG"), los talleres y las mesas de dialogo llevadas a cabo por la Agencia de Promoción de la Inversión Privada - Proinversión (Danós, 2006, p. 121).

La participación ciudadana tiene diversos significados para los grupos humanos que componen la sociedad de acuerdo a sus usos y costumbres. Sin embargo, entre sus principales características resaltan la i) transparencia, ii) comunicación, iii) responsabilidad, iv) respeto a la diversidad, v) integración de procesos y vii) respeto a disentir.

Dichas características han sido reconocidas como prioritarias, sobre la base de que constituye un derecho exigible como parte del Buen Gobierno, el mismo que parte de la regulación y la gobernanza en respuesta a las exigencias de la sociedad moderna y a la búsqueda de calidad como fuente de legitimación del Estado (Castro, 2014).

Así, la Organización para la Cooperación y el Desarrollo Económicos (en adelante, "OCDE") menciona cuáles son las actuaciones del gobierno de cara a ejercer la participación ciudadana:
Las instituciones públicas reaccionan a un público cada vez más exigente y a un control cada vez más fuerte de las acciones del Estado por parte de los medios de comunicación y de los ciudadanos. Cuando el poder público proporciona información sobre una eventual nueva política, su posible contenido, las fases de su implementación o sobre resultados obtenidos, los ciudadanos pueden mejorar, precisar y actualizar sus conocimientos. Tienen más elementos para entender y seguir la acción del gobierno. De esta manera se fortalecen los cimientos de una ciudadanía más activa.

- Al solicitar y aceptar la participación ciudadana en el proceso de toma de decisiones, las instituciones públicas se esfuerzan por responder a la expectativa de los ciudadanos que esperan que se escuche su voz y que se considere su punto de vista. Al ampliar el círculo de participantes en la elaboración de una política pública, las instituciones públicas acceden a nuevas fuentes de información. Cuando se da a todas las partes involucradas la oportunidad de contribuir en la toma de decisiones, aumenta la probabilidad de ver que se realice espontáneamente la implementación de las políticas públicas.

- Las instituciones públicas se esfuerzan por encontrar una respuesta a la disminución de la participación electoral, del número de afiliados a los partidos políticos y a los resultados de las encuestas que revelan una pérdida de confianza en las instituciones públicas. A través de la información, la consulta y la participación activa, disminuyen los obstáculos que impiden a los ciudadanos conocer, comprender, comentar y participar en los procesos de toma de decisiones. Estos factores también reducen el nivel necesario para que los ciudadanos conozcan y actúen. Les permiten darse cuenta personalmente de que la administración pública hace bien lo que, se supone, debe hacer: estar al servicio de la gente. Los ciudadanos comprueban que participar en el funcionamiento de la sociedad es rentable.

No obstante, de nada vale señalar cuál es la finalidad de la participación ciudadana y cuál es el rol del Estado, si la misma no es efectiva y evita los conflictos sociales. Sobre el conflicto, el Programa de las Naciones Unidas para el Desarrollo (en adelante, "PNUD”) señala que:

“[e]l conflicto siempre está presente, de manera latente o manifiesta, como expresión del propio dinamismo y diversidad social" (Calderón, 2012, [p.] 21). Así el conflicto social es 
inherente a la vida en sociedad y constituye una de sus manifestaciones (Wiener, 2017, [p.] 19). Por ello "el conflicto debe verse como una parte natural de la vida en sociedad, en regímenes democráticos la conflictividad social es parte de una dinámica pluralista y consecuencia lógica de un ejercicio de libertades, de capacidades de acción colectiva y de participación en el espacio público" (Tanaka, 2013, [p.] 2).

De lo anterior se deduce que los conflictos no se originan de la nada, sino que parten de la idea del ciudadano que se defiende cuando siente que se han vulnerado sus derechos. Dicho concepto rompe con el estereotipo de quien genera meras trabas hacia la inversión privada; y por el contrario, es un indicativo de que las instituciones establecidas en el actual Estado de Derecho -como lo conocemos- no están funcionando de manera adecuada $y$, por lo tanto, se debe generar consensos.

Ahora bien, antes de entrar a analizar cómo es que la participación ciudadana debe ser regulada en nuestro país, debemos situarnos en el contexto de un país como el nuestro, en el que abundan los recursos naturales pero existe una inadecuada distribución de la riqueza a causa de su aprovechamiento. Por lo tanto, al constituir un proyecto determinado, ingresos importantes para su economía, se identifican los siguientes asuntos claves como parte de la expectativa de la población aledaña:

- $\quad$ Acceso al sistema de empleo rotativo en la empresa;

- Contratación de empresas comunales como proveedores locales;

- Provisión de servicios sociales (postas médicas, aulas, agua, luz, canales riego, etc.);

- Control y uso de recursos hídricos (cantidad);

- Contaminación del medio ambiente (aire, agua, suelo, flora y fauna)

- Afectación de la salud de la población local (plomo en la sangre);

- $\quad$ Acceso a la tierra para trabajos de exploración y explotación minera;

- $\quad$ Percepción de maltrato, falta de comunicación e incumplimiento de compromisos;

- Demandas locales y regionales en torno a las posibilidades de desarrollo social y económico; $y$,

- Gestión de fideicomisos, fondos sociales y fondos del canon (Bedoya, 2014, p. 44).

Así, la búsqueda de beneficios compartidos siempre va a estar presente. Por ello, el rol preventivo de la participación ciudadana cobra vital importan- cia, lo cual va a significar que se refuerce el marco normativo conjuntamente a las políticas orientadoras a ello y que sean fácilmente aplicables en la práctica. En ese sentido, como se desarrollará más adelante, la participación ciudadana debe involucrar mecanismos garantistas que le permitan cumplir con su cometido.

\section{PARTICIPACIÓN CIUDADANA AMBIENTAL}

En nuestro ordenamiento jurídico, la participación ciudadana en el rubro ambiental es exigible desde el año 1992, dado que se desprende del Principio 10 de la Declaración de principios de la Conferencia de las Naciones Unidas sobre el Medio Ambiente y Desarrollo, celebrada en Río de Janeiro. Esta, sin embargo, recién se hizo efectiva a través de la Ley 28611, Ley General del Ambiente, sobre la base de los artículos II, III, XI del Título preliminar y el Capítulo 4; así como a través de la Ley 26821.

Luego le siguieron otras normas que reforzaron su obligatoriedad, tales como la Ley Orgánica para el aprovechamiento sostenible de los recursos naturales, específicamente su artículo 5; el artículo 48 del Decreto Legislativo 757, Ley Marco para el Crecimiento de la Inversión Privada; el artículo 5 literal g) de la Ley 28245, Ley Marco del Sistema Nacional de Gestión Ambiental, que armoniza las políticas sectoriales que coordina con la Política Nacional del Ambiente; y, el Decreto Supremo 002-2009-MINAM, Reglamento sobre Transparencia, Acceso a la Información Pública Ambiental y Participación y Consulta Ciudadana en Asuntos Ambientales.

En cuanto a los procedimientos para la aplicabilidad de la participación en el tema ambiental, vemos que estos han evolucionado junto al contexto político social, como podemos verificar de los sucesivos reglamentos de participación ciudadana.

No obstante, a pesar de que existan reglamentos de participación ciudadana sectoriales, aún existen sectores que aplican el Reglamento sobre Transparencia, Acceso a la Información Pública y Participación y Consulta Ciudadana en Asuntos Ambientales aprobado mediante Decreto Supremo 002-2009-MINAM. Este define a la participación ciudadana ambiental como aquel proceso mediante el cual los ciudadanos participan responsablemente, de buena fe y con transparencia y veracidad, en forma individual o colectiva, en la definición y aplicación de las políticas relativas al ambiente y sus componentes que se adopten en cada uno de los niveles de gobierno y en el proceso de toma de decisiones públicas sobre materias ambientales, así como en su ejecución y fiscalización. 
Para un mejor entender, a continuación, mencionaremos ejemplos de cuáles son los tipos de participación ciudadana en materia ambiental:

\section{A. Proceso de elaboración de normas}

En el ámbito nacional se establece que "[l]os proyectos de normas que regulen asuntos ambientales generales o que tengan efectos ambientales, serán puestos en conocimiento del público para recibir opiniones y sugerencias de los interesados" (Granados, 2013, 87).

Cabe resaltar que, en el proceso de elaboración de normas ambientales, se viene promoviendo la participación del público en general, incluyendo a las organizaciones no gubernamentales y agrupaciones civiles defensoras del ambiente (comunidades nativas y campesinas, así como pueblos indígenas), a efectos de realizar una adecuada ponderación entre los intereses de los grupos involucrados. Un claro caso es el de la Ley 29785, Ley del derecho a la consulta previa a los pueblos indígenas u originarios, mediante su reconocimiento en el Convenio 169 de la Organización Internacional del Trabajo (en adelante, "OIT").

\section{B. Servicio de Información Nacional de De- nuncias Ambientales - SINADA}

El artículo 38 del Reglamento de Participación Ciudadana en materia ambiental señala que "cualquier persona puede denunciar ante las instancias correspondientes el incumplimiento de alguna norma ambiental, acompañando los elementos probatorios del caso".

Dichas denuncias ambientales son remitidas al Organismo de Evaluación y Fiscalización Ambiental (en adelante, "OEFA") o a las Entidades de Fiscalización Ambiental (en adelante, "EFAS") a través de diversos medios, de acuerdo a las Reglas para la Atención de Denuncias Ambientales aprobado mediante Resolución de Consejo Directivo 015-2014OEFA/CD y sus modificaciones.

\section{Monitoreo Ambiental Participativo}

Bajo dicho supuesto, la ciudadanía participa en las labores de monitoreo ambiental que desarrolla el OEFA en ejercicio de su función evaluadora, acompañando al personal de dicha institución. Estas labores se realizan a efectos de medir la presencia y concentración de contaminantes en el ambiente.

Este procedimiento se sustenta en la Ley General del Ambiente, cuyo texto legal establece que la participación ciudadana en la fiscalización ambiental puede llevarse a cabo en las actividades de control (esto es, en las actividades de medición, muestreo y monitoreo ambiental).

\section{Proceso de certificación ambiental}

En cuanto a la participación ciudadana en el proceso de evaluación del impacto ambiental, esta se ha dado de manera progresiva. El procedimiento de participación ciudadana es aplicable a todas las etapas del proceso de evaluación de impacto ambiental (antes y durante la elaboración, durante la evaluación y después de la aprobación del estudio ambiental).

A continuación, explicaremos con mayor detalle en qué consiste este tipo de participación ciudadana ambiental.

\section{PARTICIPACIÓN CIUDADANA EN LA EVA- LUACIÓN DE IMPACTO AMBIENTAL}

Para que un proyecto extractivo se lleve a cabo debe obtener previamente una certificación ambiental expedida por la autoridad competente, dentro de la cual se incluye el Plan de Participación Ciudadana, como lo señala el SEIA, creado mediante Ley 27446, y su reglamento, aprobado mediante Decreto Supremo 019-2009-MINAM. Ello, en función del principio de prevención ambiental regulado en la Ley General del Ambiente, Ley 28611, mediante el cual se busca medir y gestionar los posibles impactos en el medio ambiente de una determinada actividad y ver si esta resulta viable, de forma ex ante.

En cuanto a la evaluación de impacto ambiental, esta se inicia a pedido de parte con la presentación del estudio ambiental debidamente categorizado, elaborado por una consultora ambiental registrada y habilitada en el sector competente.

Luego de la categorización, la Ley que crea el SEIA señala que el tipo de certificación ambiental de los proyectos de inversión públicos, privados y de capital mixto dependerá del riesgo ambiental que tengan, para lo cual establece los siguientes niveles:

a) Categoría I.- Declaración de impacto ambiental (DIA). Está definido para aquellos proyectos cuya ejecución no origina impactos ambientales negativos de carácter significativo.

b) Categoría II.- Estudio de impacto ambiental semidetallado (EIA-sd). Está regulado para aquellos proyectos cuya ejecución puede originar impactos ambientales moderados y cuyos efectos negativos pueden ser eliminados o minimizados mediante la adopción de medidas fácilmente aplicables. 
c) Categoría III.- Estudio de impacto ambiental detallado (EIA-d). Está destinado a aquellos proyectos cuyas características, envergadura y/o localización, hace que puedan originar impactos ambientales negativos significativos (en un sentido cuantitativo o cualitativo), lo que requiere un análisis profundo para revisar sus impactos y proponer la estrategia de manejo ambiental correspondiente.

Sobre este punto, es importante mencionar que, para las actividades extractivas que se encuentran contempladas dentro del marco del SEIA, cada sector económico ha dictado su propia normativa en materia de certificación ambiental y participación ciudadana, atendiendo a sus características propias y nivel de especialización.

Los mecanismos de participación ciudadana más utilizados en este rubro son la publicación de avisos, distribución de resúmenes ejecutivos y acceso público al texto completo del estudio ambiental, buzones de observaciones y sugerencias, oficinas de información, visitas guiadas, talleres informativos, audiencias públicas, encuestas o entrevistas, distribución de materiales informativos, entre otros. La implementación de dichos mecanismos se sujeta a los plazos y formas previstas en la normativa ambiental.

Es así que, dentro del procedimiento de evaluación de impacto ambiental, la aplicación de los mecanismos de participación ciudadana, además de las audiencias públicas, resulta esencial. Dichos mecanismos de participación se dan antes y durante la evaluación el proyecto, y después de la aprobación del estudio ambiental. Algunos de estos son obligatorios y otros, optativos.

En ese sentido, el proceso de evaluación de impacto ambiental incluye la realización de diversos procedimientos de participación ciudadana, los cuales deben ser dinámicos, flexibles e inclusivos y orientados al intercambio de información entre el Estado, la empresa y la población respecto de la ejecución de los proyectos de inversión. De esta manera, se busca conocer y canalizar los comentarios o aportes acerca de los proyectos de inversión para la toma de decisiones en los procesos de evaluación ambiental, así como promover el diálogo y la construcción de consensos entre las partes interesadas.

Al respecto, es preciso indicar que actualmente SENACE cuenta con una "Herramienta de Gestión Social para la Certificación Ambiental", la misma que constituye una guía que contiene acciones y proto- colos que orientan a los representantes del SENACE durante sus labores en campo, a los titulares de proyectos de inversión respecto de su relacionamiento con las poblaciones y a los actores de la sociedad civil. Con ello, se busca recuperar la confianza de la población en los estudios ambientales, generando procesos más predecibles, dinámicos y eficientes.

\section{A. Enfoque Intercultural}

La pluralidad cultural en nuestro país se encuentra reconocida en el artículo 2 inciso 19 de la Constitución Política del Perú y en el Convenio 169 de la OIT sobre Pueblos Indígenas y Tribales en Países Independientes.

Es por ello que, a través de la Ley Marco de Modernización de la Gestión del Estado, Ley 27658, y la Política Nacional de Transversalización del Enfoque Intercultural, aprobada por el Ministerio de Cultura en el año 2015, el Estado busca mejorar la gestión pública para construir un Estado democrático, descentralizado y al servicio de la ciudadanía, con el fin de garantizar el ejercicio de derechos sin ningún tipo de discriminación y reducir las desigualdades existentes.

Al respecto, se ha acordado dar prioridad a los pueblos indígenas y a la población afroperuana, ya que son grupos históricamente discriminados y que se encuentran en especial situación de vulnerabilidad, dado sus altos índices de pobreza y desempleo de acuerdo al Instituto Nacional de Estadística e Informática - INEI ${ }^{3}$.

Por ejemplo, en el 2013, el porcentaje de pobreza entre la población indígena amazónica ascendió a $60,5 \%$ (6 de cada 10 personas) de la población total. Esto quiere decir que la probabilidad de ser pobre en las personas de origen indígena es alarmante ${ }^{4}$. Similar situación se presenta en el acceso a servicios básicos y en servicios de salud, en los cuales solo el 3,1\% de la población indígena amazónica accede a los servicios de agua potable, alcantarillado y energía eléctrica. La situación de las y los afroperuanos hoy en día no es muy diferente, según el Estudio Especializado para Población Afroperuana (en adelante, "EEPA") realizado por el Ministerio de Cultura y el Grupo de Análisis para el Desarrollo GRADE en el 2014.

Bajo dicho supuesto, se ha visto necesaria la incorporación del Enfoque Intercultural en la gestión pública. Así, se incorpora en el proceso de participación ciudadana a través de la realización de un

\footnotetext{
Población desocupada según etnia, 2013.

4 Según la Línea de Base de Brechas Sociales por Origen Étnico en el Perú, Ministerio de Cultura.
} 
intercambio abierto y respetuoso de opiniones entre grupos con diferentes tradiciones y orígenes étnicos, culturales, religiosos y lingüísticos, priorizándose el diálogo y la accesibilidad de la información en el idioma propio del área de influencia social. Por ello, mediante la Resolución de Presidencia Ejecutiva 00005-2018-SENACE/PE, se aprobó la "Guía de Participación Ciudadana con Enfoque Intercultural para la Certificación Ambiental”"5.

La mencionada Guía enriquece el proceso de participación ciudadana para la certificación ambiental, ya que propicia y fomenta el diálogo equitativo entre todos los actores sociales del área de influencia de un determinado proyecto de inversión y genera sinergias entre el titular, el Estado y las poblaciones aledañas. Entre sus objetivos se encuentran: (i) fortalecer la capacidad de gestión intercultural del Estado peruano, (ii) reconocer positivamente la diversidad cultural y lingüística, (iii) eliminar la discriminación étnico-racial e, (iv) incluir socialmente a los pueblos indígenas y la población afroperuana.

En el caso de proyectos extractivos, es a partir del reconocimiento de los pueblos indígenas y sus dere- chos colectivos desde donde parte la aplicación de un proceso de participación ciudadana intercultural.

En atención a ello, se requiere analizar lo siguiente ${ }^{6}$ : (i) continuidad histórica (preexistencia del Estado), (ii) conexión territorial (ocupación de un territorio desde tiempos ancestrales), (iii) instituciones distintivas (sociedades que retienen o conservan algunas o todas sus instituciones propias), y (iv) criterio subjetivo de auto identificación (conciencia de grupo colectivo de poseer una identidad) ${ }^{7}$.

Por ello, una vez identificado el tipo de población a la cual se le va aplicar un determinado mecanismo de participación ciudadana, se debe verificar los siguientes aspectos (ver cuadro adjunto).

\section{B. Enfoque de Género}

En materia de igualdad de género, a nivel nacional, la norma más importante es la Constitución (inciso 2 del artículo. 2 y artículo 121), la cual reconoce el derecho a la igualdad y no discriminación por razón de sexo y el principio de representación de género en los concejos regionales y municipales.

\begin{tabular}{|c|c|}
\hline Accesibilidad & $\begin{array}{l}\text { Se debe tener en cuenta las particularidades geográficas que caracterizan los territorios an- } \\
\text { dinos y amazónicos, así como el tiempo que utilizan para el desarrollo de sus actividades tra- } \\
\text { dicionales, tales como la agricultura y ganadería, para programar los talleres informativos o } \\
\text { audiencias públicas. } \\
\text { Por otro lado, si bien es cierto, se debe respetar la representación designada por cada comuni- } \\
\text { dad, se debe promover la participación efectiva de la mujer indígena, quien es muchas veces } \\
\text { es la más afectada. }\end{array}$ \\
\hline Oralidad & $\begin{array}{l}\text { La participación ciudadana debe considerar la oralidad pues es una de las principales caracte- } \\
\text { rísticas de todos los pueblos indígenas. Ello aunado al índice de analfabetismo. }\end{array}$ \\
\hline Bilingüismo & $\begin{array}{l}\text { En el caso de los pueblos indígenas el uso de las lenguas originarias con una adecuada traduc- } \\
\text { ción y/o interpretación es de utilidad práctica en la comprensión de la información referida a la } \\
\text { evaluación del impacto ambiental }{ }^{8} \text {. }\end{array}$ \\
\hline Transparencia y buena fe & $\begin{array}{l}\text { Informar de qué tratan los mecanismos de participación ciudadana y cuál es su finalidad. Co- } \\
\text { rregir los mitos sobre la "licencia social". } \\
\text { Resulta fundamental que los compromisos pactados se cumplan en el tiempo establecido bajo } \\
\text { el rol fiscalizador del Estado. }\end{array}$ \\
\hline
\end{tabular}

Fuente: Guía de Participación Ciudadana con Enfoque Intercultural para la Certificación Ambiental.

5 Cabe señalar que la presente Guía recibió sus aportes de la "Hoja de Ruta del SENACE con los Pueblos Indígenas 2016-2017".

6 De acuerdo a la Guía Metodológica del Ministerio de Cultura sobre el Convenio 169 de la OIT, para la identificación de quienes constituyen pueblos indígenas u originarios.

7 Cabe precisar que, el Ministerio de Cultura ha identificado a la fecha la existencia de 55 pueblos indígenas u originarios, de ellos 51 son originarios de la Amazonía y 4 de los Andes, registrados dentro de la Base de Datos de Pueblos Indígenas u originarios (BDPI), la cual es referencial y orientadora, no siendo esta una lista cerrada.

8 EI SENACE ha elaborado el documento denominado "Guías para la presentación del Resumen Ejecutivo del EIAd", el cual contiene ambos documentos aprobados mediante Resolución Directoral 036-2017-SENACE/DCA y la Resolución Directoral 139-2017-SENACE/DCA. Recuperado de: http://www.senace.gob.pe/wpcontent/uploads/2018/03/Guias-parala-presentacion-del-Resumen-Ejecutivo-del-EIA-d.pdf 
Mientras que a nivel internacional, se tiene a los acuerdos de la Plataforma de Beijing ${ }^{9}$, la Convención sobre la Eliminación de todas las Formas de Discriminación contra la Mujer, la Convención Interamericana para Prevenir, Sancionar y Erradicar la Violencia contra la Mujer - Convención de Belém do Pará, el Pacto Internacional de Derechos Civiles y Políticos, el Pacto Internacional de Derechos Económicos, Sociales y Culturales, entre otros acuerdos internacionales, concretando así el Perú su compromiso con la erradicación de las brechas de género y con toda forma de discriminación por sexo.

Es por ello que, a través del Decreto Supremo 0272007-PCM, se estableció una serie de Políticas Nacionales de obligatorio cumplimiento para las entidades del Gobierno Nacional en materia de igualdad de hombres y mujeres.

Asimismo, el Ministerio de la Mujer y Poblaciones Vulnerables (en adelante, "MIMP"), ente rector en materia de igualdad de género, aprobó el Plan Nacional de Igualdad de Género 2012-2017 (en adelante, "PLANIG") a través del Decreto Supremo 004-2012-MIMP. Este tiene entre sus objetivos estratégicos el incremento de la participación de mujeres y hombres en la toma de decisiones y la participación política y ciudadana, así como la valoración del aporte de las mujeres en el manejo sostenible de los recursos naturales, los mismos que deben estar reflejados en nuestro sistema legal.

Es así como el SENACE, en el marco de estas políticas nacionales, ha elaborado un documento titulado "Lineamientos para Promover la Participación de la Mujer en el Proceso de Certificación Ambiental", a través del cual se busca promover la participación efectiva de las mujeres en el proceso de certificación ambiental de proyectos de inversión bajo su competencia.

En ese caso, se han tomado distintas variables para facilitar y asegurar una participación efectiva de las mujeres en la certificación ambiental bajo la premisa que toda política, programa y proyecto afectan a la mujer y al hombre de manera diferenciada.

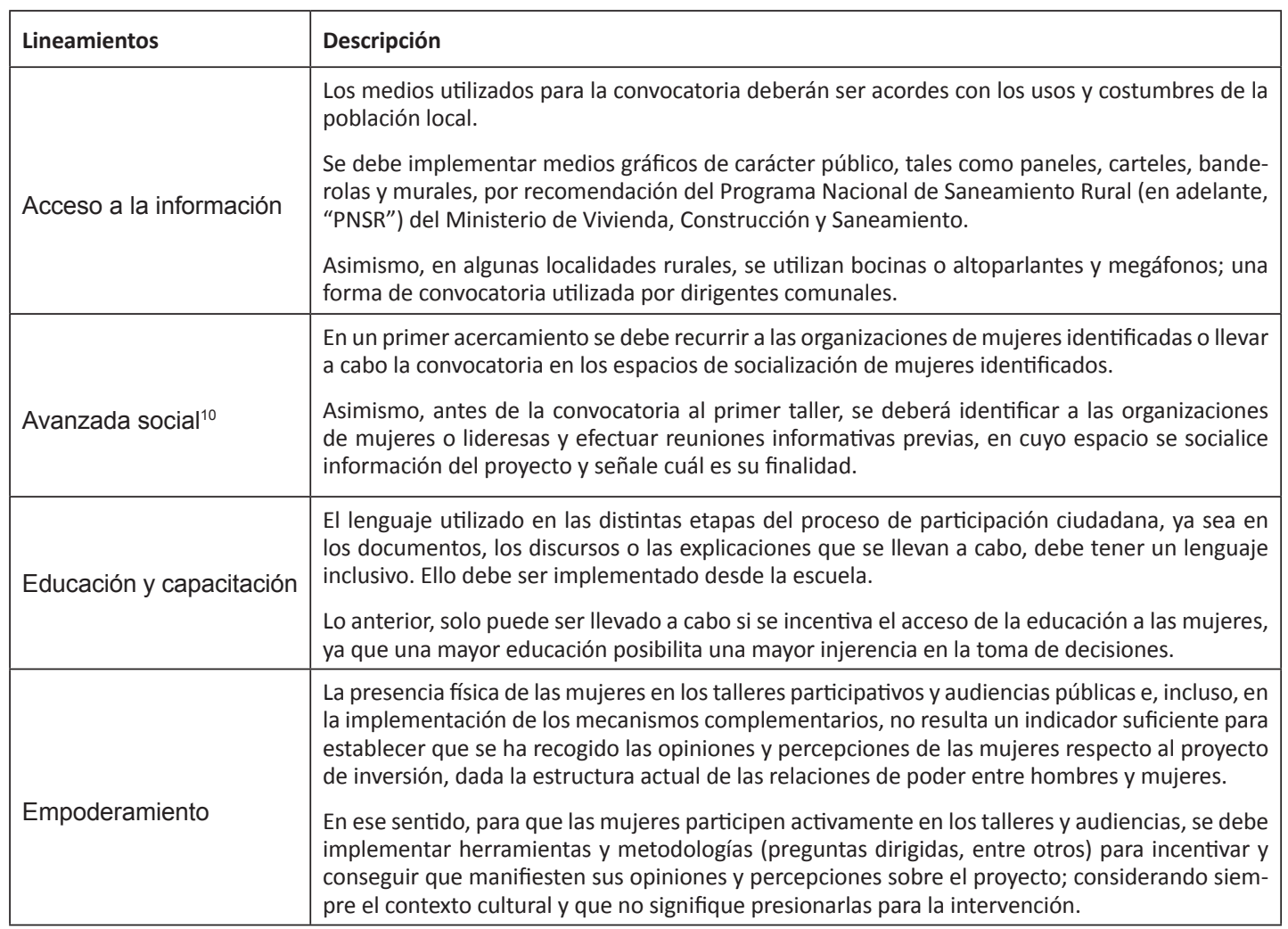

$9 \quad$ La Plataforma de Beijing implicó la incorporación del enfoque de género en las políticas públicas, marcando una diferencia sustancial en relación a todos los compromisos internacionales que buscaban la superación de barreras y obstáculos para la igualdad de género.

10 La Avanzada Social consiste en una presencia temprana del equipo de evaluadores del SENACE en campo, con la finalidad de tener un primer contacto con la población que habita en el área de influencia del proyecto, generar un clima de confianza y evaluar el contexto social en el que la población se desenvuelve, de acuerdo a "Herramientas de Gestión Social para la Certificación Ambiental”, 2016, pp. 16-17. 


\begin{tabular}{|l|l|}
\hline $\begin{array}{l}\text { Limitaciones en la asis- } \\
\text { tencia }\end{array}$ & $\begin{array}{l}\text { Uso diferenciado del tiempo debido a la carga laboral no remunerada que realizan en el hogar } \\
\text { por tener que cuidar a sus hijos y/o familiares (adultos mayores), dado que la gran mayoría de } \\
\text { mujeres son amas de casa y se retiran o asisten de manera intermitente las audiencias públicas } \\
\text { y talleres participativos }{ }^{11} \text {. } \\
\text { Por lo tanto, será importante verificar la justificación en torno a la fecha, lugar y horario de los } \\
\text { mecanismos de participación ciudadana propuestos. }\end{array}$ \\
\hline $\begin{array}{l}\text { La identificación tempra- } \\
\text { na de situaciones de ries- } \\
\text { go para las mujeres, tales } \\
\text { como violencia, feminici- } \\
\text { dio, conflictos sociales, } \\
\text { prostitución, etc.) }\end{array}$ & $\begin{array}{l}\text { Para que haya una mayor participación de las mujeres, es necesario que se garantice } \\
\text { su integridad física y emocional. } \\
\text { tuaciones de riesgo, en coordinación con las autoridades locales y regionales, el Minis- } \\
\text { terio Público, la Policía Nacional del Perú, entre otras autoridades, pudiendo considerar } \\
\text { la participación de ONGs relacionados a la problemática. }\end{array}$ \\
\hline
\end{tabular}

Fuente: Lineamientos para Promover la Participación de la Mujer en el Proceso de Certificación Ambiental.

Como hemos visto, resulta de vital importancia dar prioridad a este grupo, dada la situación de desigualdad existente entre mujeres y hombres en el Perú, lo cual se refleja en las Estadísticas con Enfoque de Género del Instituto Nacional de Estadística e Informática (en adelante, "INEI").

- $\quad$ Al respecto, en el cuarto trimestre del año 2016, se registró que la asistencia de las mujeres, desde inicial a secundaria era menor a las de hombres.

- De igual forma, se estableció que era el grupo con más problemas de salud crónicos $(7,4$ puntos porcentuales más que los hombres).

La situación anteriormente descrita se agrava si no puede abastecerse de los ingresos suficientes para acceder a niveles de calidad de vida suficientes. Por ejemplo, solo en empleo, de cada 100 hombres en edad de trabajar, 81 integran la fuerza laboral, mientras que las mujeres que participan en la actividad económica representan 63 de cada 100 , existiendo una brecha de 18 hombres más que mujeres.

\section{OBLIGACIÓN DEL ESTADO}

Como señalamos anteriormente, el procedimiento de participación ciudadana es aplicable a todas las etapas del proceso de evaluación de impacto ambiental (antes y durante la elaboración y después de la aprobación del EIA).

En esa línea, se tiene que, para la evaluación del impacto ambiental, el titular del proyecto de inversión tiene la obligación de presentar el plan de participación ciudadana (en adelante, "PPC"), que será aprobado por la autoridad competente, en el que se establecerán los mecanismos de participación ciudadana que se aplicarán durante el proceso de evaluación ambiental, tomando en cuenta el área de influencia del proyecto y las características de las poblaciones, las particularidades del proyecto, entre otros aspectos (Calle y Ryan, 2016, p. 178).

Como vemos, el PPC aprobado contiene los mecanismos de participación ciudadana que van a ser aplicados durante el ciclo de vida del proyecto y la forma como van a ser ejecutados. Dicha obligación debe ser fiscalizada por el Estado, ya que no solo representa el mero cumplimiento de una obligación formal sino que constituye un derecho fundamental ${ }^{12}$.

La participación ciudadana se funda en la democracia, el mismo que constituye un derecho humano; por ende, los estados tienen la obligación de a actuar de una manera determinada o abstenerse de emprender ciertas acciones con la finalidad de promover y proteger este derecho.

Al respecto, cabe tener presente que, conforme lo ha señalado reiteradamente por el Comité de Derechos Económicos, Sociales y Culturales de Naciones Unidas, los derechos humanos imponen tres tipos o niveles de obligaciones a los Estados: respetar, proteger y cumplir.

En cuanto a la obligación de respetar, requiere que el Estado se abstenga de interferir en el disfrute del derecho, ya sea directa o indirectamente;

11 A modo de ejemplo, en el proyecto "Corredor de Conservación Purús-Manu", integrado por el World Wildlife Fund (WWF), Pronaturaleza, CARE Perú, Frankfurt Zoological Society (FZS) y la Organización Regional AIDESEP-Ucayali (ORAU), en alianza con la organización ProPurús, en el marco de la Iniciativa para la Conservación en la Amazonía Andina (ICAA II), se ha identificado como un factor de éxito para la asistencia de las mujeres durante las reuniones y eventos de capacitación, el cuidado infantil de sus hijos e hijas menores.

12 El Estado puede incurrir en responsabilidad internacional con respecto a la exigencia de la participación ciudadana, tal y como se ha visto en el Caso Pueblo Indígena De Sarayaku, Resolución del 17 de junio o el de la Comunidad Mayagna (Sumo) Awas Tingni Vs. Nicaragua. Fondo, Reparaciones y Costas. Sentencia del 31 de agosto de 2001. 
mientras que la obligación de proteger demanda que el Estado adopte medidas para evitar que terceros obstaculicen dicho disfrute. Por su parte, la obligación de cumplir requiere que el Estado adopte medidas legislativas, administrativas, judiciales, presupuestales y otras que busquen la completa realización de los derechos (Consejo Económico y Social de las Naciones Unidas, 2000).

Para garantizar que los Estados cumplan con sus obligaciones en la materia, a nivel regional, tenemos a la Comisión Interamericana de Derechos Humanos, que es la que se encarga de monitorear y reportar la situación de los derechos humanos en todos los Estados miembros de la Organización de los Estados Americanos (en adelante, “OEA"), y es el primer órgano que acoge el procedimiento de peticiones individuales (denuncias); y a la Corte Interamericana de Derechos Humanos, como un tribunal internacional para examinar las denuncias de violaciones de los derechos humanos ocurridas en los Estados americanos que reconozcan su competencia.

De modo que la idea que subyace a un Estado que cumple sus obligaciones en cuanto al fomento de la participación ciudadana efectiva, es la implementación del Buen Gobierno. Dicho concepto, según el Código Iberoamericano de Buen Gobierno, está referido a "aquel que busca y promueve el interés general, la participación ciudadana, la equidad, la inclusión social y la lucha contra la pobreza, respetando todos los derechos humanos, los valores y procedimientos de la democracia y el Estado de Derecho".

Es así como la Carta Iberoamericana de Participación Ciudadana en la Gestión Pública señala que la participación ciudadana efectiva va de la mano con una gestión pública de calidad. Ello quiere decir que las ciudadanas y los ciudadanos, sin ningún tipo de exclusión, tienen el derecho de participar en el ciclo de diseño y mejora del servicio que ofrecen los entes de la Administración Pública, garantizando su efectividad.

De similar modo, la participación ciudadana efectiva se encuentra relacionada con el principio de gobernanza ambiental, el cual menciona lo siguiente:

Ley General del Ambiente, Ley 28611: Artículo XI.- Del principio de gobernanza ambiental

El diseño y aplicación de las políticas públicas ambientales se rigen por el principio de gobernanza ambiental, que conduce a la armonización de las políticas, instituciones, normas, procedimientos, herramientas e información de manera tal que sea posible la participación efectiva e integrada de los actores públicos y privados, en la toma de decisiones, manejo de conflictos y construcción de consensos, sobre la base de responsabilidades claramente definidas, seguridad jurídica y transparencia.

De la norma se infiere que, la necesidad de implementar una participación ciudadana efectiva va más allá de crear normas para su implementación; requiere que durante su ejecución, se brinden mecanismos para asegurar que esta se dé de forma inclusiva. Para ello, se necesitará una readaptación a este nuevo enfoque.

Y para lograr este nuevo enfoque, lo que se busca es fortalecer institucionalmente al Estado, lograr administraciones públicas más transparentes $\mathrm{y}$ promover instrumentos necesarios para una mayor participación de la sociedad civil, más aún en el proceso de toma de decisiones, el cual muchas veces responde a un grupo minoritario.

Esta situación permitirá que sectores de la sociedad civil tradicionalmente excluidos de los procesos de toma de decisiones (como las mujeres, los pueblos indígenas, adultos mayores, afro descendientes, etc.) sean tomados en cuenta de manera real, de tal forma que las instituciones del gobierno garanticen la plena vigencia y protección de los derechos humanos de aquellos que han sido excluidos de forma permanente.

Por ello, es interesante cómo instituciones como el SENACE han ido adaptándose al nuevo modelo de Estado que se busca lograr a través del Buen Gobierno, no solo en cuanto a simplificación administrativa y calidad regulatoria, sino garantista de los derechos humanos a través de la dación de normas y directivas que regulan la participación ciudadana en la evaluación del impacto ambiental.

La participación ciudadana ambiental efectiva va permitir que se reduzca la tasa de conflictos sociales y se eviten casos como "Tía María" y "Las Bambas".

Por ejemplo, en el caso "Las Bambas", la empresa (Xstrata) debía obtener un EIA-d, el mismo que fue aprobado mediante Resolución Directoral 0732011-MEM/AAM. Sin embargo, durante el proceso de evaluación del impacto ambiental, se detectaron deficiencias que devinieron en un conflicto social de proporciones mayores.

Algunas de las observaciones fueron las siguientes:

- Compromisos sociales incumplidos con respecto al anexo $\mathrm{k}$. 
- $\quad$ No se informó del nuevo dueño de la empresa y su nueva política de relaciones comunitarias $^{13}$.

- No se utilizaron buenos métodos de negociación.

- Poca presencia del Estado al momento de fiscalizar el plan de participación ciudadana.

- $\quad$ El incumplimiento de sus obligaciones ambientales.

- Actos de corrupción y mala utilización del canon.

- Reasentamiento poblacional ineficaz (Wiener, 2017,p. 85).

En cuanto al caso del Proyecto Minero "Tía María", se identificó lo siguiente:

- Lucha por el recurso hídrico del Valle del Tambo.

- Actos violentos por falta de información y poca confianza en el privado.

- $\quad$ No se tenía en claro el objetivo del proceso de participación ciudadana y, menos aún, el de la audiencia pública.

- Observaciones que habían sido no advertidas por el evaluador pero sí por Organismos Internacionales.

- Mal manejo del conflicto social por parte del Estado y renuencia para llegar a un acuerdo.

- La gestión previa de la empresa había dejado áreas contaminadas, por lo que perdió credibilidad (Calle y Ryan, 2016, p. 178).

Como puede verse, en ambos casos no existe participación ciudadana efectiva, dada la limitada capacidad de las instituciones del Estado garante y de la propia sociedad para concretar la incorporación de la opinión pública en los procesos de toma de decisiones.

Asimismo, resulta importante definir el rol de los actores involucrados y la lucha de intereses que puede terminar por desvirtuar la finalidad de la participación ciudadana.

Es por ello que, si bien es cierto, los mecanismos para viabilizar la participación ciudadana efectiva que viene implementando SENACE (Enfoque de Género y Enfoque Intercultural) son incipientes, constituyen un paso importante en la concreción de las metas del País ${ }^{14}$ y servirá de ejemplo para que otras instituciones del Estado implementen un sistema más garantista.
Ello, puesto que se busca institucionalizar las herramientas de participación ciudadana, utilizando preferentemente las estructuras y organizaciones ya existentes. Sobre todo, porque se busca crear y/o perfeccionar mecanismos de participación para la gestión ambiental que puedan ser ejecutados desde un inicio y no solamente cuando el ciudadano se siente afectado (principio de prevención); ya que la dinámica cambia y las posibilidades de solución se reducen.

\section{CONCLUSIONES}

- Un EIA de calidad, que se de durante un proceso transparente, demostrará la real dimensión de los impactos ambientales de los proyectos de inversión y las estrategias de mitigación, corrección y reducción de riesgos, generando un clima de mayor confianza y evitando con ello futuros conflictos socioambientales.

Asimismo, dado que el EIA constituye un expediente altamente técnico, el Estado debe explorar formas a través de las cuales se brinde asistencia técnica a las poblaciones ubicadas en el área de influencia de los proyectos de inversión que facilite la comprensión de los EIA.

- $\quad$ En ese sentido, la actuación del Estado es primordial a fin de definir mecanismos informativos eficaces durante los procedimientos de participación ciudadana, a través de los cuales se enfatice las funciones de las autoridades competentes durante los procesos de evaluación ambiental y responsabilidades que ello involucra. Además, el Estado debe garantizar que los acuerdos adoptados se cumplan, así como la posibilidad de apelación por parte del ciudadano disconforme.

Por lo tanto, entendiendo que los mecanismos de participación ciudadana son instrumentos destinados a la difusión de información y generación de espacios para la formulación de opiniones, observaciones, sugerencias, comentarios y otros aportes orientados a evaluar la viabilidad de un proyecto que afecta los medios de vida de un sector de la población, su implementación no debe ser considerada una mera formalidad sino que debe ser ejecutada de forma que se garantice su efectividad.

Xstrata es reemplazada por Minerals and Metals Group - MMG.

14 El Plan Nacional de Acción Ambiental (PLANAA Perú 2011 - 2021). 
Bajo este enfoque, los mecanismos de participación ciudadana que se implementen deberán garantizar además:

a) El efectivo involucramiento de los pueblos indígenas u originarios en las zonas de influencia de proyectos determinados, considerando su cosmovisión y sus prioridades de desarrollo, lo cual cobra importancia si se trata de sus tierras y su modo de subsistencia a partir de ella.

b) La plena incorporación de la perspectiva de género en la gestión del medio ambiente, dado el papel de la mujer en las cuestiones ambientales y su exclusión del proceso de toma de decisiones en las cuales son las más perjudicadas dadas las desigualdades existentes en nuestra sociedad. Una de estas, asociada al bajo nivel educativo y a un menor acceso al empleo remunerado.

De esta forma, se tendrá una real dimensión de las opiniones, comentarios, observaciones y sugerencias para la viabilidad de un determinado proyecto, los cuales deberán ser tomados en cuenta durante la evaluación del impacto ambiental de manera obligatoria. De lo contrario, no solo el titular del proyecto será responsable, sino también el Estado como garante.

Cabe señalar que entre los beneficios de la participación ciudadana efectiva se encuentran: la contribución a la equidad, asegurando la presencia de los más desfavorecidos; prevención de la corrupción, pero sobretodo la identificación más concreta de las necesidades; y, los intereses de los destinatarios.

- En atención a ello, SENACE ha implementado una serie de mecanismos para fomentar la participación ciudadana efectiva. De esta forma, se viene colaborando en la formación de un Estado más eficiente, transparente y participativo, brindando a la ciudadanía información oportuna y adecuada, a fin de que pueda intervenir activamente en la gestión ambiental y en el proceso de toma de decisiones que ello conlleva.

Por ello, aunque aún persiste el gran reto de seguir trabajando en el fortalecimiento de los mecanismos de participación ciudadana en temas ambientales, la dación de normas y directivas por parte de instituciones claves como SENACE es un gran paso y debe servir de modelo para otros sectores como modelo de buen gobierno.

\section{REFERENCIAS}

Alayza Moncloa, A. (2009). Minería, comunidades y participación. Consulta y consentimiento previo, libre e informado en el Perú. En: Centro Andino de Acción Popular - CAAP, Centro Latinoamericano de Ecología Social - CLAES (Ed). Extractivismo, política y sociedad. Quito: Centro Andino de Acción Popular - CLAES, pp. 157-185.

Bedoya García, C. (2014). Evolución y tendencias de los conflictos sociales y ambientales en el Perú: una lectura general. En: I. Ormachea Choque, J. Caravedo Chocano, G. Moreno Hermoza, C. Bedoya García. Minería, conflicto social y diálogo. Lima: ProDiálogo, Prevención y Resolución de Conflictos, pp. 25-45.

Calderón Gutiérrez, F. (Coord). (2012). La protesta social en América Latina. Cuaderno de Prospectiva Política I. Buenos Aires: Siglo Veintiuno Editores.

Calle Valladares, I. y Ryan, D. (2016). La participación ciudadana en los procesos de evaluación de impacto ambiental: análisis de casos en 6 países de Latinoamérica. Lima: Sociedad Peruana de Derecho Ambiental.

Castro Barriga, C. D. A. (2014). Legalidad, buenas prácticas administrativas y eficacia en el sector público: un análisis desde la perspectiva jurídica del buen gobierno. En: C.D.A., Castro Barriga. (Ed). Buen Gobierno y Derechos Humanos. Nuevas perspectivas en el derecho público para fortalecer la legitimidad democrática de la administración pública en el Perú. Lima: Facultad de Derecho de la Pontificia Universidad Católica del Perú, Instituto de Democracia y Derechos Humanos de la Pontificia Universidad Católica del Perú, Instituto de Asuntos Públicos y Buen Gobierno.

Consejo Económico y Social de las Naciones Unidas. (2000). Observación General 14: El derecho al disfrute del más alto nivel de salud (Artículo 12 del Pacto Internacional de Derechos Económicos Sociales y Culturales). Ginebra: Naciones Unidas.

Danós Ordóñez, J. (2006). La participación ciudadana en el ejercicio de las funciones administrativas en el Perú. Revista de Derecho Administrativo 1, pp. 121-164.

Defensoría del Pueblo. (2007). Informe Extraordinario: Los conflictos socio ambientales por actividades extractivas en el Perú. 
Granados Mandujano, M. (2013). Promoción de la participación ciudadana en la fiscalización ambiental. En: Organismo de Evaluación y Fiscalización Ambiental (OEFA). El nuevo enfoque de la fiscalización ambiental. Lima: Organismo de Evaluación y Fiscalización Ambiental, pp. 87-101.

Instituto Interamericano de Derechos Humanos. (2002). Participación ciudadana. San José: Instituto Interamericano de Derechos Humanos.

Instituto Nacional de Estadística e Informática. (2014). Características de la población desempleada. Perú: Evolución de los Indicadores de Empleo e Ingresos por Departamento, 20042013, pp. 101-110.

Ministerio de Cultura. (2015). Línea de Base de Brechas Sociales por Origen Étnico en el Perú. Lima.

Ministerio de Cultura. (2014). Etapa de identificación de pueblos indígenas u originarios - Guía Metodológica. Lima.

Oficina del alto comisionado de las Naciones Unidas para los Derechos Humanos. (2008). Prácticas de buen gobierno para la protección de los derechos humanos. Nueva York y Ginebra: Naciones Unidas. Recuperado de: https:// www.ohchr.org/Documents/Publications/ GoodGovernance_sp.pdf.

Organización y Cooperación para el Desarrollo Sostenible (OCDE). (2015). Caminos de Desarrollo - Estudio multidimensional del Perú. Volumen I. Recuperado de: https://www.oecd.org/dev/ MDCR\%20PERU\%20Principales\%20mensages_FINAL.pdf.

Pérez, S. (1999). Gobierno y Participación Ciudadana. Quórum 68, pp. 178.

Servicio Nacional de Certificación Ambiental para las Inversiones Sostenibles (SENACE). (2018). Guía de Participación Ciudadana con Enfoque Intercultural para la Certificación Ambiental. Recuperado de: https://www.senace.gob.pe/ archivos/?wpfb_dl=10924.

Servicio Nacional de Certificación Ambiental para las Inversiones Sostenibles (SENACE). (2018). Lineamientos para promover la Participación de la Mujer en el Proceso de Certificación Ambiental. Recuperado de: http://www.senace.gob.pe/wp-content/uploads/2017/08/ Lineamientos-para-Promover-la-Participacionde-la-Mujer-en-el-Proceso-de-CertificacionAmbiental.pdf.
Servicio Nacional de Certificación Ambiental para las Inversiones Sostenibles (SENACE). (2016). Herramientas de Gestión Social para la Certificación Ambiental. Recuperado de: http://www. senace.gob.pe/wp-content/uploads/2017/01/ herramientas-titular.pdf.

Wiener Ramos, L. (2017). Problemas de gobernanza en una actividad extractiva (Tesis para optar por el grado de Magíster en Ciencia Política y Gobierno). Lima: Pontificia Universidad Católica del Perú.

\section{LEGISLACIÓN, JURISPRUDENCIA Y OTROS DOCU- MENTOS LEGALES}

Decreto Legislativo 757. Ley Marco para el Crecimiento de la Inversión Privada. En: Diario El Peruano, 13 de noviembre de 1991.

Decreto Supremo 002-2009-MINAM. Decreto Supremo que aprueba el Reglamento sobre Transparencia, Acceso a la Información Pública Ambiental y Participación y Consulta Ciudadana en Asuntos Ambientales. En: Diario El Peruano, 17 de enero de 2009.

Decreto Supremo 003-2015-MC. Decreto Supremo que aprueba la Política Nacional para la Transversalización del Enfoque Intercultural. En: Diario El Peruano, 28 de octubre de 2015.

Decreto Supremo 004-2012-MIMP. Decreto Supremo que aprueba el "Plan Nacional de Igualdad de Género 2012-2017". En: Diario El Peruano, 18 de agosto de 2012.

Decreto Supremo 019-2009-MINAM. Reglamento de la Ley 27446, Ley del Sistema Nacional de Evaluación de Impacto Ambiental. En: Diario El Peruano, 25 de setiembre de 2009.

Decreto Supremo 027-2007-PCM. Decreto Supremo que define y establece las Políticas Nacionales de obligatorio cumplimiento para las entidades de Gobierno Nacional. En: Diario El Peruano, 25 de marzo de 2007.

Ley 26821. Ley Orgánica para el Aprovechamiento Sostenible de los Recursos Naturales. En: Diario El Peruano, 10 de junio de 1997.

Ley 27446. Ley del Sistema Nacional de Evaluación de Impacto Ambiental. En: Diario El Peruano, 23 de abril de 2001.

Ley 27658. Ley marco de Modernización de la Gestión del Estado. En: Diario El Peruano, 30 de enero de 2002. 
Ley 28245. Ley marco del Sistema Nacional de Gestión Ambiental. En: Diario El Peruano, 8 de junio de 2004.

Ley 28611. Ley General del Ambiente. En: Diario El Peruano, 15 de octubre de 2015.

Ley 29968. Ley de creación del Servicio Nacional de Certificación Ambiental para las Inversiones Sostenibles. En: Diario El Peruano, 19 de diciembre de 2012.
Resolución de Consejo Directivo 015-2014-OEFA/ $\mathrm{CD}$. Reglamento para la atención de denuncias ambientales presentadas ante el Organismo de Evaluación y Fiscalización Ambiental - OEFA. En: Diario El Peruano, 9 de abril de 2014.

Resolución Ministerial 339-2014-MC. Orientaciones para la Implementación de Políticas Públicas para Población Afroperuana. En: Diario EI Peruano, 27 de setiembre de 2014. 